\title{
The Coupling Coordination Degree Measurement of Society-Economy-Ecosystem of Regional National Forest Park in Heilongjiang Province
}

\author{
Chen CHEN, Zhenhua QIAO, Haitao SUN*
}

\begin{abstract}
In order to estimate the comprehensive benefits brought by forest parks to the society, economy, and ecology of a certain area, this paper innovatively constructed a social-economic-ecological composite system of forest parks in Heilongjiang Province. The entropy method is used to determine the weight of each index, the coupling coordination degree model is used to analyze the coupling and coordination degree of the social, economic, and ecological benefits of forest parks in Heilongjiang Province from 2010 to 2018. In addition, the LSTM neural network model is used to predict the development trend of the coupling coordination degree of the composite system from 2019 to 2021. Research shows that from 2010 to 2018, the forest park composite system was in a state of "high coupling and low coordination" for a long time; from 2019 to 2021 , it is predicted that the degree of coupling of the composite system will decrease slightly and the degree of coordination will increase.
\end{abstract}

Keywords: composite system; coupling coordination degree; forest park; LSTM neural network model

\section{INTRODUCTION}

In 2019, the Central Committee of the Communist Party of China issued the "Guiding Opinions on Establishing a Natural Reserve System with National Parks as the Main Body", proposing the establishment of a unified and standardized nature protection system. The forest park is an important part of the construction of the natural protected area system and a project that has attracted wide attention at home and abroad in recent years, which can bring multiple benefits to mankind in society, economy, and ecology. Furthermore, it is also an important way to realize the construction of ecological civilization under the background of increasing demand for green ecology. The ecological environment and human economic society are closely related, they form a complex system through mutual influence. A good ecosystem brings positive external effects to residents, and after receiving feedback from the ecosystem, local residents will respond with a good response from the ecosystem. For example, residents will have a strong willingness to pay (WTP) for the construction of forest parks, resulting in an effect of 1 $+1>2[1]$. For the application of the coordination degree of the composite system, some scholars have applied it in the ecological survey of China. Huang Dechun et al. used China's 2001-2015 panel data to conduct a combined analysis of the economic system and the ecosystem, and measured the coordination degree of the ecologicaleconomic complex system [2]. Li Yue established a coupling degree model to clarify the synergy between the conversion of farmland to forest project and the agricultural ecological, economic, and social system [3]. Lv Xiao took the Tarim River Basin in Xinjiang as an example, and used the coupling degree evaluation model to evaluate and analyze the coupling development of the agricultural land eco-economic system in the Tarim River Basin [4]. Chen Bing constructed an evaluation index system for ecological civilization construction and urbanization took 26 cities in the Yangtze River Delta City Group as research objects [5]. With the rapid development of artificial intelligence, deep learning algorithms are widely used in image recognition and classification, machine translation, speech recognition and other fields [14]. LSTM neural network model is a kind of deep learning algorithm. Then, it is used for time series data analysis and prediction in many fields due to strong nonlinear mapping ability and strong self-learning ability. For example: Treasury bond yield forecast [15], air passenger travel index forecast [16], consumer confidence index forecast [17], traffic flow forecast [18], stock forecast [19], etc. Compared with traditional regression models and traditional neural network models, the prediction results of the LSTM have the best fitting effect and have obvious advantages in the prediction effects on the same trend.

Forest parks and human economic society have formed a complex system of mutual coordination, common development, and mutual restraint. It is necessary to conduct a comprehensive analysis and evaluation of the development of the composite system, but currently there are few studies on it. Therefore, this paper takes Heilongjiang Province as an example to establish a national forest park social-economic-ecological complex system, which uses the coupling coordination degree model and the LSTM neural network model to analyze the evolution and development trend of the coupling coordination degree of the composite system. It can comprehensively evaluate and accurately predict the comprehensive benefits of forest parks to the region.

\section{RESEARCH AREA AND DATA SOURCES 2.1 Research Area}

Heilongjiang Province is located in the northern part of northeastern China, with latitude $43^{\circ} 26^{\prime}-53^{\circ} 33^{\prime}$ north and longitude $121^{\circ} 11^{\prime}-135^{\circ} 05^{\prime}$ east. It straddles the four major water systems of Heilongjiang, Wusuli River, Songhua River, and Suifen River and the total area is 473,000 square kilometers. It belongs to the cold temperate and temperate continental monsoon climate. As of 2018, the regional gross product (GDP) of Heilongjiang Province was 1,636.16 billion yuan, and the per capita GDP was 43,274 yuan. Heilongjiang Province is one of the largest forestry provinces in China, with a total forestry management area of 31.75 million hectares, accounting for $2 / 3$ of the province's land area. Moreover, the area of forest land is 20.07 million hectares, the total volume of standing timber is 1.5 billion cubic meters, the forest coverage rate reaches $43.6 \%$, and the forest area, total forest volume, and timber production rank among the top in the country. 
Meanwhile, there are more than 100 species of forest trees, and more than 30 species of high utilization value. It is the most important state-owned forest area and the largest timber production base in the country.

\subsection{Data Sources}

The data comes from the "China Statistical Yearbook", "China Forestry Statistical Yearbook" and "Heilongjiang Province Statistical Yearbook".

\section{RESEARCH METHODS \\ 3.1 Indicator System}

Forest parks have the functions of recreation and ecological protection. In addition, the establishment of forest parks will bring positive spillover effects to the local economy and residents' lives. In order to evaluate the social rationally, economic and ecological multiple benefits of forest parks, this paper establishes three subsystems, which include the social subsystem, economic subsystem and ecological subsystem.

The ecological benefits of forest parks mainly refer to the obvious environmental benefits that the construction of forest parks can bring, such as improving air quality, reducing soil erosion, increasing carbon sinks, etc. Therefore, the forest park ecological subsystem includes the green coverage rate of the built-up area, the national forest park area, the total afforestation area of the year and the forest appearance transformation area. The social welfare benefits of forest parks are mainly reflected in the ecological education function of forests and the harmonious and orderly experience of nature. The greater the number of tourists received, the higher the degree of natural happiness that tourists experience [6], so the social subsystem can be represented by the total number of annual receptions of the forest park, the total number of employees, and the forest park area per capita. Then, the more tourists, the greater the driving effect on the local economy, including the driving and radiation effect on the construction of surrounding infrastructure and the construction of surrounding scenic spots. Therefore, the regional economic subsystem can be measured by the total forest parks income, the tourism resource density, the income of forestry tourism and the output value of other industries, which refers to related literature [6-10], and establishes an index system as shown in Tab. 1.

\subsection{Entropy Method}

The entropy method is an objective weighting method, which can avoid the disadvantages of subjective weighting, such as the need for rich experience, and it can solve the problem of information overlap with multiple indicators. The calculation formula is as follows:

(1) Suppose $m$ indicators and $n$ years. Use the standardized data to calculate the proportion of the $j$-th index in year $t$ :

$$
P_{j t}=\frac{X_{j t}}{\sum_{t=1}^{n} X_{j t}}
$$

(2) Calculate the entropy value of the $j$-th index:

$e_{j}=-k \sum_{t=1}^{n} P_{j t} \ln \left(P_{j t}\right)$

Among these, $k=1 / \ln n, e_{j} \geq 0$.

(3) Calculate the difference coefficient value of the $j$ th index:

$d_{j}=1-e_{j}$

(4) Calculate the weight of the $j$-th index:

$$
\omega_{j}=\frac{d_{j}}{\sum_{j=1}^{m} d_{j}}
$$

Initially, the original data was standardized to eliminate the interference caused by different dimensions. Then, according to the entropy method, the weight value of each order parameter was determined, as shown in Tab. 1.

\begin{tabular}{|c|c|c|c|c|}
\hline Subsystem & Order parameter & Standard & Unit & Weights \\
\hline \multirow{3}{*}{$\begin{array}{l}\text { Economic } \\
\text { subsystem }\end{array}$} & Tourism resource density & $\begin{array}{c}\text { Number of National Forest Parks and } \\
\text { Number of Scenic Spots Above Grade A }\end{array}$ & / & 0.0951 \\
\hline & Total Forest Park Income & $*$ & Ten thousand yuan & 0.2059 \\
\hline & Drive the output value of other industries & * & Ten thousand yuan & 0.1363 \\
\hline \multirow{3}{*}{$\begin{array}{c}\text { Social } \\
\text { subsystem }\end{array}$} & Forest park area per capita & * & $\mathrm{m}^{3}$ & 0.0006 \\
\hline & Total number of employees & & 1 & 0.0080 \\
\hline & The total number of annual receptions in the forest park & $*$ & Million people & 0.0786 \\
\hline \multirow{4}{*}{$\begin{array}{l}\text { Ecological } \\
\text { subsystem }\end{array}$} & Green coverage rate of built-up area & $* *$ & $\%$ & 0.0001 \\
\hline & Total afforestation area of the year & $*$ & Hectares & 0.3637 \\
\hline & National Forest Park Area & $* *$ & Hectares & 0.0123 \\
\hline & Forest appearance transformation area & *** & day & 0.0994 \\
\hline
\end{tabular}

Table 1 The index system and weights of the social-economic-ecological coordination system of forest parks

Note: * indicates that the data refers to the "China Forestry Statistical Yearbook", ** indicates that the data refers to the "Statistical Yearbook of Heilongjiang Provincial Bureau of Statistics".

\subsection{Coupling Coordination Degree Model Construction}

As for the existing measurement methods of the coordination degree of the composite system, this paper selects the coordination degree measurement model of the composite system based on the sequence parameter. Because the coordination degree measurement model of the composite system based on the order parameter can 
simplify the complex relationships within the system, the coordination degree of the system can be calculated scientifically and effectively.

The composite system can be abstracted as $S=\left\{S_{1}\right.$, $\left.S_{2}, \ldots, S_{p}\right\}$. This paper designs three subsystems: economic subsystem is $S_{1}$, social subsystem is $S_{2}$ and ecological subsystem is $S_{3}$. And suppose the order parameter in the development process of the subsystem is $e_{i}=\left(e_{i 1}, e_{i 2}, \ldots\right.$, $\left.e_{i n}\right)$, among these, $n \geq 1, \alpha_{i j} \leq e_{i j} \leq \beta_{i j}(i=1,2, \ldots, n), \alpha_{i j}, \beta_{i j}$ is the upper and lower limits of the sequence parameter component. Assuming that the order parameter can be divided into two types, whose $e_{i 1}, e_{i 2}, \ldots, e_{i k}$ are positive indicators, the larger the value, the greater the order of the system; $e_{i k+1}, e_{i \mathrm{k}+2}, \ldots, e_{i n}$ are negative indicator, the larger the value, the lower the order of the system. The order model is as follows:

$$
\mu_{i}\left(e_{j i}\right)=\left\{\begin{array}{l}
\frac{e_{j i}-\alpha_{j i}}{\beta_{j i}-\alpha_{j i}}, i \in(1, k) \\
\frac{\beta_{j i}-e_{j i}}{\beta_{j i}-\alpha_{j i}}, i \in(k+1, n)
\end{array}\right.
$$

Among these, $\mu_{j}\left(e_{j}\right) \in[0,1]$, the larger the value, the higher the degree of order of the order parameter, and the greater the contribution to the order of the system.

For the order degree of the subsystem, there are geometric average method and linear weighting method. This paper uses the entropy method to give the weight value of the order parameter, and then uses the linear weighting method to give the order degree of the subsystem.

$\mu_{j}\left(e_{j}\right)=\sum_{j=1}^{n} \omega_{j} \mu_{j}\left(e_{j i}\right), \omega_{j} \geq 0, \sum_{j=1}^{n} \omega_{j}=1$

Among these, $\mu_{\mathrm{j}}\left(e_{j}\right) \in[0,1]$, the greater the value, the greater the degree of order of the subsystem.
Refer to the principle of synergy, and calculate the coupling degree of the system based on the existing results. The principle of the coupling degree is to calculate the coupling degree by referring to the physics capacitycoupling concept and the capacity coupling coefficient model, and the interdependence between the systems has clarified.

Among these, $C$ is the degree of coupling. $e_{j}$ is the order degree of existing subsystems.

$C_{n}=\left[\frac{e_{1} \cdot e_{2} \cdot \ldots, \cdot e_{n}}{\prod\left(e_{i}+e_{j}\right)}\right]^{\frac{1}{n}}$

In order to prevent high coupling and low synergy, it is also necessary to measure the degree of synergy. The measure of the degree of synergy of the composite system is to measure the order of the subsystems from a dynamic perspective. Assuming that the order degree of the subsystem at the initial moment is $u_{j}^{0}\left(h_{j}\right), j=1,2, \ldots, k$. At time $t_{1}$, the system has a degree is $u_{j}^{1}\left(h_{j}\right), j=1,2, \ldots, k$. Then the coordination degree of the composite system in period $t_{0}-t_{1}$ is defined as $\mathrm{cm}$, and its measurement method:

$c m=\varphi \sqrt[n]{\left|\prod_{j=1}^{n} u_{j}^{1}\left(h_{j}\right)-u_{j}^{0}\left(h_{j}\right)\right|}$

Among these, $\varphi=\frac{\min \left[u_{j}^{1}\left(h_{j}\right)-u_{j}^{0}\left(h_{j}\right) \neq 0\right]}{\left|\min \left[u_{j}^{1}\left(h_{j}\right)-u_{j}^{0}\left(h_{j}\right) \neq 0\right]\right|}$.

The value range of the total synergy $\mathrm{cm}$ of the composite system is $[-1,1]$, and the larger the value, the higher the degree of synergy development of the composite system, and vice versa. After standardizing the data, using the composite system model, the results in Tab. 2 are obtained.

Table 2 Coupling and coordination degree of the social-economic-ecological complex system of Heilongjiang National Forest Park

\begin{tabular}{|c|c|c|c|c|c|c|}
\hline years & $\begin{array}{l}\text { Economic } \\
\text { subsystem }\end{array}$ & $\begin{array}{c}\text { Social } \\
\text { subsystem }\end{array}$ & $\begin{array}{l}\text { Ecological } \\
\text { subsystem }\end{array}$ & $\begin{array}{l}\text { Coupling degree of } \\
\text { composite system }\end{array}$ & $\begin{array}{l}\text { Coordination degree of } \\
\text { composite system }\end{array}$ & Coupling strength and coordination strength \\
\hline 2010 & 0.0718 & 0.0038 & 0.2460 & 0.3706 & 0.2341 & 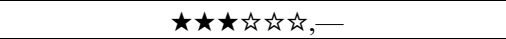 \\
\hline 2011 & 0.0226 & 0.0174 & 0.1041 & 0.7140 & 0.2077 & 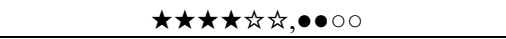 \\
\hline 2012 & 0.0761 & 0.0309 & 0.2881 & 0.6658 & 0.3393 & 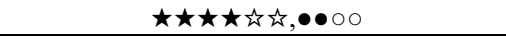 \\
\hline 2013 & 0.1725 & 0.0353 & 0.4236 & 0.6520 & 0.4272 & 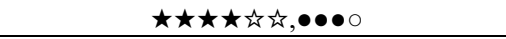 \\
\hline 2014 & 0.0882 & 0.0505 & 0.0876 & 0.9693 & 0.2857 & 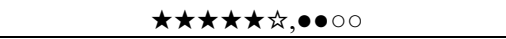 \\
\hline 2015 & 0.2503 & 0.0617 & 0.0781 & 0.8165 & 0.3514 & 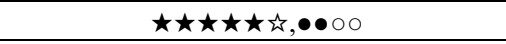 \\
\hline 2016 & 0.2779 & 0.0682 & 0.0684 & 0.7891 & 0.3553 & 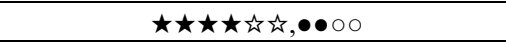 \\
\hline 2017 & 0.3426 & 0.0060 & 0.0995 & 0.3808 & 0.2743 & 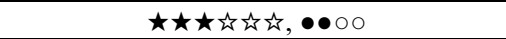 \\
\hline 2018 & 0.4334 & 0.0827 & 0.2057 & 0.8090 & 0.4881 & 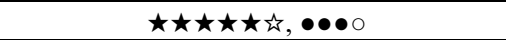 \\
\hline
\end{tabular}

Note: $\star \star \star \star$ 放 means the coupling degree, the more $\star$ means the higher the coupling degree; $\bullet \bullet \bullet \circ \circ$ means the coordination degree, the more $\bullet$ means the higher the coordination degree; These results are divided according to the classification standard and type of coupling coordination degree (Tab. 3-(1), Tab. 3-(2)).

Table 3-(1) Classification standard of coupling degree of composite system

\begin{tabular}{|c|c|c|c|c|c|c|}
\hline Coupling Degree $C$ & $C=0$ & $0<C \leq 0.3$ & $0.3<C \leq 0.5$ & $0.5<C \leq 0.8$ & $0.8<C<1$ & $C=1$ \\
\hline Coupling level & $\begin{array}{l}\text { The degree of coupling is } \\
\text { extremely small, and the system } \\
\text { is unconnected and develops } \\
\text { disorderly }\end{array}$ & $\begin{array}{c}\text { Low-level } \\
\text { coupling }\end{array}$ & $\begin{array}{c}\text { Antagonism } \\
\text { stage }\end{array}$ & Run-in stage & $\begin{array}{c}\text { High-level coupling } \\
\text { stage, high-intensity } \\
\text { interaction between } \\
\text { the two }\end{array}$ & $\begin{array}{l}\text { Achieving a benign } \\
\text { coupling and moving } \\
\text { towards a new stage }\end{array}$ \\
\hline
\end{tabular}


In order to more intuitively judge the type of coordination degree of Heilongjiang Province's socialeconomic-ecological complex system, this paper classifies the coupling strength and coordination level of the system [11-13], as shown in Tab. 3-(1) and Tab. 3-(2).

Table 3-(2) Classification standards and types of coordination degree of composite systems

\begin{tabular}{|c|c|c|}
\hline Coordination Degree & Type & \multirow{2}{*}{ Coordination level } \\
\hline $0-0.19$ & Severe imbalance & \multirow{2}{*}{ Imbalance recession level } \\
\hline $0.19-0.39$ & On the verge of deregulation & Transition level \\
\hline $0.4-0.59$ & Primary coordination & Coordinated development level \\
\hline $0.6-0.79$ & Intermediate coordination & . \\
\hline
\end{tabular}

\subsection{LSTM Neural Network Coupling Coordination Degree Prediction Model}

The LSTM network structure adopts the mechanism of control gates, which is composed of memory cells, input gate, output gate, and forget gate [20], (Fig.1). In addition, this paper takes the social-economic-ecological composite system index and coupling coordination degree of Heilongjiang Forest Park as the experimental object, and selects the LSTM neural network model to predict and analyze the ecological-economic-society coupling coordination degree of Heilongjiang Forest Park from 2019 to 2021. It is hoped that the future development trend of the social-economic-ecological complex system of forest parks in Heilongjiang Province can be obtained, so as to guide and help the future policy planning of forest parks through the predictive model.

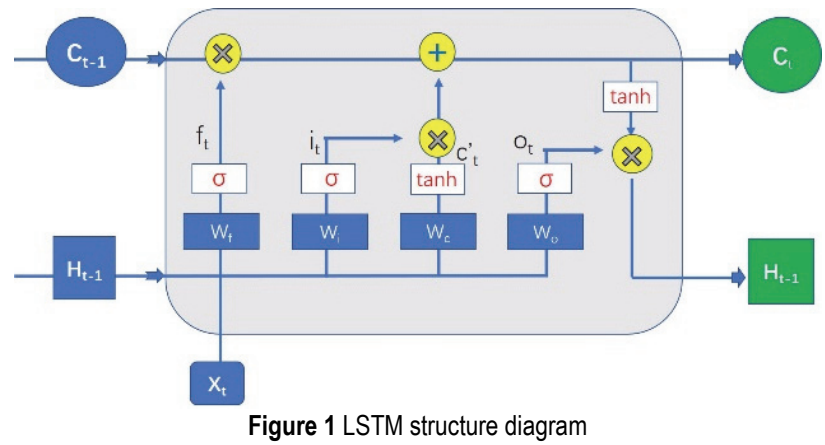

Among these, $X_{t}$ represents the input at time $t$, and $h_{t}$ represents the state value of the cell at time $t, \sigma$ represents the feedforward network layer with activation function sigmoid, $i_{t}$ is input gate. $f_{t}$ is forget gate and $O_{t}$ is output gate, $\boldsymbol{W}$ is the weight matrix of the input process, tanh is the hyperbolic tangent function. $h_{t}$ is the output hidden state vector and $C_{t}$ is the adjusted and updated content.

Firstly, calculate the value of the input gate $i_{t}$ and the candidate state value of the input cell $C_{t}^{\prime}$ at time $t$, the formula is as follows:

$$
\begin{aligned}
& i_{t}=\delta\left[\boldsymbol{W}_{i} \cdot\left(X_{t}, h_{t-1}\right)+b_{i}\right] \\
& C^{\prime}{ }_{t}=\tanh \left[\boldsymbol{W}_{c} \cdot\left(X_{t}, h_{t-1}\right)+b_{c}\right]
\end{aligned}
$$

Secondly, calculate the activation value $f_{t}$ of the forget gate at time $t$, the formula is as follows:

$$
f_{t}=\delta\left[\boldsymbol{W}_{f} \cdot\left(X_{t}, h_{t-1}\right)+b_{f}\right]
$$

From the above two steps of calculation, the cell state update value $C_{t}$ at time t can be calculated, and the formula is as follows:

$$
C_{t}=i_{t} \cdot C_{t}^{\prime}+f_{t} \cdot C_{t-1}
$$

After the cell state update value is calculated, the value of the output gate can be calculated at last, and the calculation formula is as follows:

$$
\begin{aligned}
& O_{t}=\delta\left[\boldsymbol{W}_{o} \cdot\left(X_{t}, h_{t-1}\right)+b_{o}\right] \\
& h_{t}=O_{t} \cdot \tanh \left(C_{t}\right)
\end{aligned}
$$

Through the above calculations, LSTM can effectively use the input to make it have a long-term memory function.

The operating environment of the model is MATLAB2018b in this paper. In addition, it adopts a multivariable and multi-step prediction mechanism. In addition, each prediction step is 3 steps, and 11 influence factors are used to predict the degree of coupling or coordination. Then, the network data needs to normalize before inputting. Furthermore, the mapminmax function is used to preprocess the input and output data, and then the data is divided into proportions. The ratio of the training set to the test set is 5:4 (65 data points from 2010 to 2015 as training set, 52 data points from 2016 to 2018 as verification set) and the weight loss rate of the hidden layer is 0.2 . In order to prevent over-fitting, after the hidden layer, a fully connected layer is used to set the feature dimension of the predicted value step, and a network regression layer for continuous value prediction is designed, and finally the output result is denormalized. At the same time, this paper uses the Adam optimization algorithm to solve the LSTM model value. The maximum number of traversal samples is 1000 , the batch sample size is 50 , the initial learning rate is 0.001 , and the learning rate decay rate is 0.8 after 500 cycles.

This paper uses min-max normalization to process the original data to eliminate dimensional differences. The linear transformation of the original data so that the result falls into the interval $[0,1]$, and the formula is as follows:

$X=\frac{x-\min }{\max -\min }$

Among these, max is the maximum value of the features in the sample data, and $\min$ is the minimum value of the features in the sample data. $x$ is the original data, and $X$ is the normalized data.

The prediction performance evaluation index of its model adopts root mean square error (RMSE) and mean 
absolute error $(M A E)$ to evaluate the accuracy of prediction results.

Among these, the calculation formulas of RMSE and $M A E$ are as follows:

$$
\begin{aligned}
& \text { RMSE }=\sqrt{\frac{1}{N} \sum_{t=1}^{N}\left(X_{\text {predicition }, t}-X_{\text {real }, t}\right)^{2}} \\
& M A E=\frac{1}{N} \sum_{i=1}^{N}\left|\left(X_{\text {prediction, } i}-X_{\text {real }, i}\right)\right|
\end{aligned}
$$

\section{RESULT ANALYSIS}

4.1 Time Evolution Characteristics of the Coupling Coordination Degree of the Social-EconomicEcological Complex System

1. From the perspective of the time evolution trend of the coupling degree of the composite system, the coupling degree curve develops toward the outer dimension, and the coupling degree is continuously increasing, with an average annual increase of 0.05 units. According to the classification criteria in Tab. 3-(1), the ecological-welfare system of Heilongjiang Forest Parks was in the antagonism stage in 2010, 2011-2013 was in the running-in stage. However, the coupling degree reached 0.96 and entered a high-level coupling stage, and the two interacted strongly in 2014. Although the degree of coupling declined slightly from 2015 to 2018 , most of the years were in the highly coupled stage.

2. From the perspective of the time evolution trend chart of the synergy degree of the composite system, the coordination degree curve develops outward, and the synergy degree is on the rise, with an average annual increase of 0.03 units. Moreover, there are two peaks located in 2013 and 2018. According to the classification criteria in Tab. 3-(2), the social-economic-ecological complex system of Heilongjiang National Forest Park was on the verge of imbalance from 2010 to 2012 and 2014 to 2017. In addition, 2013 and 2018 were the primary coordination stages and were in transition but the overall development is good.

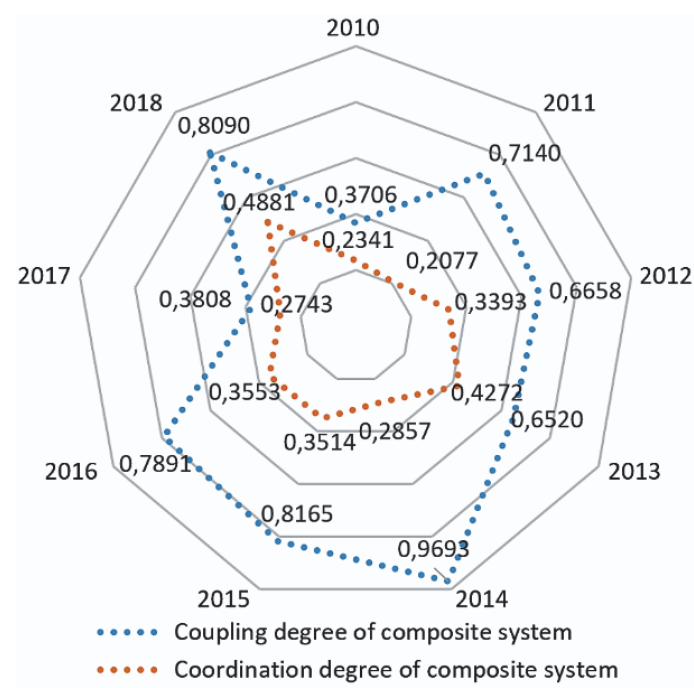

Figure 2 Time evolution trend diagram of the coupling coordination degree of the composite system

3. "High coupling, low coordination": It can be seen from Fig. 2 that the coordination degree curve is always inside the coupling degree curve, and the linear distance is relatively long, and the composite system is in a state of "high coupling, low coordination". However, it is worth noting that the coordination degree is in a breakthrough period in 2018, which shows that certain efforts are needed such as the government's increase in environmental protection, the increase in afforestation area, and the development of the forest health industry, etc., to achieve synergistic interaction and virtuous circle between the two in the later period.

\subsection{The Prediction Results of LSTM Neural Network Model}

Use MATLAB2018b to perform LSTM prediction, and the results are as follows (Tab. 4-(1), Tab. 4-(2), Tab. 5, Tab. 6, Fig. 3-(1) and Fig. 3-(2)).

\subsubsection{LSTM Results of Coupling Degree and Coordination Degree of Composite System}

Table 4-(1) Composite System LSTM Network Model Coordination Results

\begin{tabular}{|c|c|c|c|c|}
\hline Year & $\begin{array}{c}\text { Predictive } \\
\text { value }\end{array}$ & $\begin{array}{c}\text { Actual } \\
\text { value }\end{array}$ & $\begin{array}{c}\text { Absolute } \\
\text { error }\end{array}$ & Relative error \\
\hline 2010 & 0.2356 & 0.2341 & 0.0015 & 0.0064 \\
\hline 2011 & 0.2222 & 0.2077 & 0.0145 & 0.0697 \\
\hline 2012 & 0.3407 & 0.3393 & 0.0013 & 0.004 \\
\hline 2013 & 0.4051 & 0.4272 & 0.0221 & 0.0517 \\
\hline 2014 & 0.2942 & 0.2857 & 0.0085 & 0.0299 \\
\hline 2015 & 0.3504 & 0.3514 & 0.001 & 0.0029 \\
\hline 2016 & 0.3492 & 0.3553 & 0.0061 & 0.0172 \\
\hline 2017 & 0.2845 & 0.2743 & 0.0102 & 0.0372 \\
\hline 2018 & 0.4669 & 0.4881 & 0.0212 & 0.0435 \\
\hline
\end{tabular}

It can be seen from the actual value, predicted value, absolute error and relative error value of the coordination degree that the absolute error distribution interval is [0.001, $0.0221]$, and the relative error distribution interval is [0.004 $0.070]$. The errors of the predicted values are all within a reasonable range. Using the LSTM neural network model to predict the coordination degree of the forest park's ecological-economic-social complex system has a good effect, and the results are highly reliable.

Table 4-(2) Composite System LSTM Network Model Coupling Degree Results

\begin{tabular}{|c|c|c|c|c|}
\hline Year & $\begin{array}{c}\text { Predictive } \\
\text { value }\end{array}$ & Actual value & $\begin{array}{c}\text { Absolute } \\
\text { error }\end{array}$ & Relative error \\
\hline 2010 & 0.4204 & 0.3706 & 0.0499 & 0.1345 \\
\hline 2011 & 0.6639 & 0.7141 & 0.0502 & 0.0703 \\
\hline 2012 & 0.6671 & 0.6658 & 0.0013 & 0.0019 \\
\hline 2013 & 0.6703 & 0.6520 & 0.0183 & 0.0281 \\
\hline 2014 & 0.9114 & 0.9693 & 0.0579 & 0.0597 \\
\hline 2015 & 0.8008 & 0.8165 & 0.0157 & 0.0193 \\
\hline 2016 & 0.797 & 0.7891 & 0.0079 & 0.01 \\
\hline 2017 & 0.4869 & 0.3808 & 0.1061 & 0.2787 \\
\hline 2018 & 0.7554 & 0.8090 & 0.0536 & 0.0662 \\
\hline
\end{tabular}

It can be possible from the coupling degree to calculate the actual result, prediction result, the absolute error and the relative error value, the absolute error distribution interval $[0.001,0.106]$ and the relative error distribution interval $[0.002,0.279]$. The relative error was relatively large in 2017 , which is 0.2787 . This is because the coupling degree of that year was not high, and there were large 
changes compared with other years, so that it affected the forecast results. However, it was an accidental situation and the error in other years is within a reasonable range. Therefore, the prediction result of the coupling degree of the forest park economy-ecology-society complex system in 2019-2021 is accurate by using the LSTM.

\subsubsection{Evaluation of the Prediction Performance of the LSTM Network Model}

\begin{tabular}{|c|c|c|c|}
\multicolumn{4}{|c}{ Table 5 Accuracy of forecast results (2019-2021) } \\
\begin{tabular}{|c|c|c|c|}
\hline LSTM network \\
predicts absolute \\
mean error \\
$(M A E)$
\end{tabular} & $\begin{array}{c}\text { LSTM network } \\
\text { predicts the } \\
\text { average absolute } \\
\text { error percentage } \\
(M A P E)\end{array}$ & $\begin{array}{c}\text { LSTM } \\
\text { network } \\
\text { prediction root } \\
\text { mean square } \\
\text { error }(R M S E)\end{array}$ \\
\hline $\begin{array}{c}\text { Coordination } \\
\text { Degree }\end{array}$ & 0.0144 & 0.0437 & 0.0123 \\
\hline $\begin{array}{c}\text { Coupling } \\
\text { Degree }\end{array}$ & 0.0601 & 0.1114 & 0.0507 \\
\hline
\end{tabular}

It is shown that the average relative error MAE of prediction of the multivariate multi-step LSTM model established in this paper is within $6 \%$, the root mean square error of prediction is within 0.05 , from Tab. 5 . In addition, the index evaluation results are acceptable. It means that the establishment of the prediction model is relatively reasonable, which can provide reference and basis for the prediction of regional coupling and coordination.

\subsubsection{LSTM Network Model Composite System Coupling and Coordination Degree Prediction Results}

Tab. 6 shows the change trend of the coupling and coordination degree of the Heilongjiang Forest Park socialeconomic-ecological complex system from 2019 to 2021 predicted by the LSTM network model. Combining the standards in Tab. 3-(1) and Tab. 3-(2), it is analyzed that the coupling degree of the forest parks in Heilongjiang Province will decrease slightly and the coordination degree will increase from 2019 to 2021 . It is expected to exceed 0.5 , which is the critical period of coordination development from primary coordination to good coordination.

Table 6 The prediction results of the coupling coordination degree of the composite system

\begin{tabular}{|c|c|c|}
\hline Year & $\begin{array}{c}\text { Coupling degree } \\
\text { prediction result }\end{array}$ & $\begin{array}{c}\text { Coordination degree } \\
\text { prediction result }\end{array}$ \\
\hline 2019 & 0.8198 & 0.4703 \\
\hline 2020 & 0.7964 & 0.4854 \\
\hline 2021 & 0.7819 & 0.4951 \\
\hline
\end{tabular}

Through Fig. 3-(1) and Fig. 3-(2), we can intuitively see the future development trend of coupling and coordination, and observe that the results of the LSTM network model are in line with the true value from 2010 to 2018.

Coupling and coordination are two characteristics of a composite system. Only when the degrees of coupling and coordination are improved at the same time, the composite system can fully break through and become a higher-level composite system. Therefore, according to the "short board theory", only by efforts to improve coordination, increase coordination and coupling simultaneously and to achieve strong coupling and high coordination, will it be possible to break through existing obstacles and improve the system.

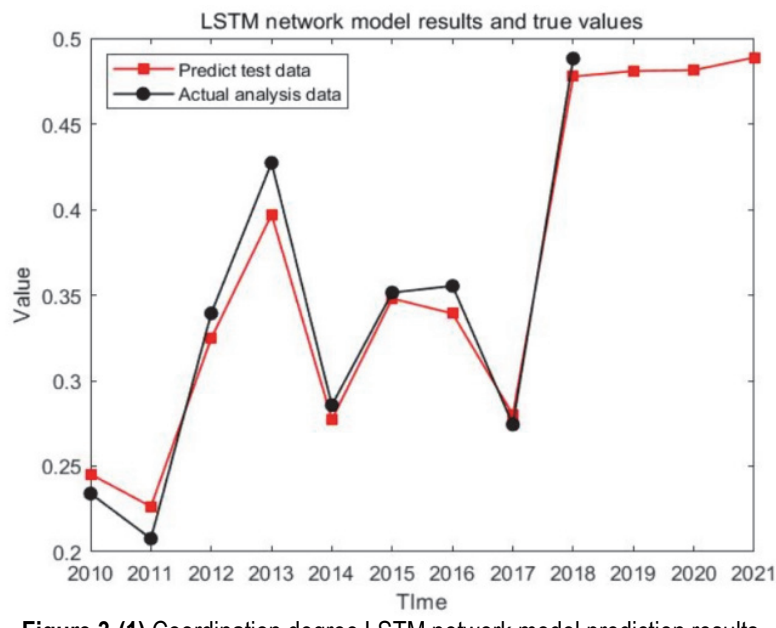

Figure 3-(1) Coordination degree LSTM network model prediction results

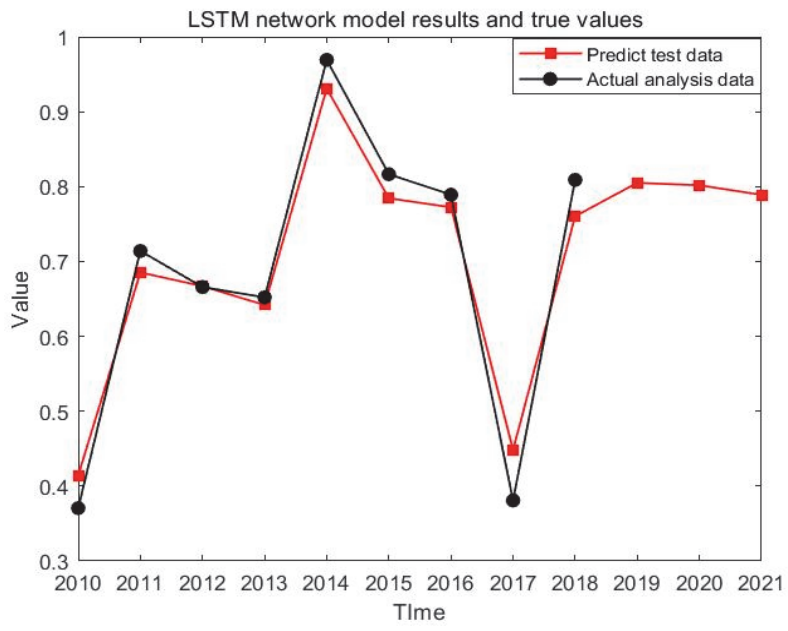

Figure 3-(2) Coupling degree LSTM network model prediction results

\section{CONCLUSIONS AND PROSPECTS}

Forest parks are an excellent choice to build a livable city while improving the ecological quality, economic level and the happiness of residents. The paper established a social-economic-ecological complex system of the forest parks and analyzed the coupling and coordination degree of the system by using the relevant data of Heilongjiang Province from 2010 to 2018. At the same time, the LSTM network prediction model is used to predict the development trend of the complex system coordination and coupling degree from 2019 to 2021 . The conclusions are as follows:

(1) The coupling coordination degree of the socialeconomic-ecological complex system of forest parks is generally on the rise. It is currently in a transitional period. Furthermore, the past two years have been a key stage for the ecological-welfare system to enter a high-level coupling and coordinated development, and it is expected to enter a high intensity, interactive, high quality, and coordinated development.

(2) Judging from the prediction results of the LSTM network model, the coupling degree will drop slightly from 2019 to 2021, and the coordination degree will reach 0.5 , which will become a critical period for good coordination.

(3) It is recommended that Heilongjiang Province 
should seize the opportunity of the country to build beautiful China by starting with the national forest park as a breakthrough, creating a national characteristic forest park signboard and making good use of the rich forest resources and developing eco-tourism. It cannot only drive local economic development, but also provide resource services for local residents and tourists to experience forest health and healing.

\section{REFERENCES}

[1] Tao, Z., Yan, H., \& Zhan, J. (2012). Economic Valuation of Forest Ecosystem Services in Heshui Watershed using Contingent Valuation Method. Procedia Environmental Sciences, 13, 2445-2450. https://doi.org/10.1016/j.proenv.2012.01.233

[2] Dechun, H., Haodong, H., \& Ming, T. (2018). An Empirical Study on the Coordinated Development of China's Ecological-Economy - Based on the Coordination Degree Model of Composite Systems. Environmental Protection. 46(14), 39-44. https://doi.org/10.14026/j.cnki.0253-9705.2018.14.008

[3] Yue, L., et al. (2018). Research on the Synergy between the Conversion of Cropland to Forest Project and Agricultural Eco-economic and Social System - Taking Ansai County as an Example. Journal of Natural Resources, 33(07), 11791190. https://doi.org/10.31497/zrzyxb.20180107

[4] Xiao, L. \& Xinping, L. (2010). Evaluation of the coupling development of agricultural land eco-economic system Taking the Tarim River Basin in Xinjiang as an example. Resources Science, 32(08), 1538-1543.

[5] Bing, C., et al. (2019). Research on the coordinated development of ecological civilization construction and urbanization in the Yangtze River Delta City Group. Resources and Environment in the Yangtze River Basin, 28(03), 530-541. https://doi.org/10.11870/cjlyzyyhj201903004

[6] Zhenmin, D. \& Xiujuan, H. (2016). Research on the Impact of Capital Investment on Tourism Efficiency of China's Forest Parks. Resources Science, 38(07), 1363-1372. https://doi.org/10.18402/resci.2016.07.16

[7] Ansheng, H., Siren, L., \& Huibing, Z. (2018). Analysis of influencing factors of technical inefficiency of China's provincial forest parks under multiple output goals. Resources Science, 40(08), 1595-1607. https://doi.org/10.18402/resci.2018.08.10

[8] Liangjun, L. (2019). Research on Ecological Welfare Performance Evaluation of Major Cities in China - Empirical Analysis Based on PCA-DEA Method and Malmquist Index. Exploration of Economic Issues, 2.

[9] Ling, S., et al. (2014). Economic Value Evaluation of Ecological Compensation Based on Tourists' Willingness to Pay - Taking Wuhan Sushan Temple National Forest Park as an example. Resources and Environment in the Yangtze River Basin, 23(02), 180-188. https://doi.org/10.11870/cjlyzyyhj201402004

[10] Zhenmin, D., Xiujuan, H., \& Jiajia, Z. (2018). The theoretical validity of CVM in evaluating the recreational value of forest scenic spots - Taking Fuzhou National Forest Park as an example. Forestry Science, 54(08), 133-141. https://doi.org/10.11707/j.1001-7488.20180815

[11] Liming, X. \& Xianpeng, Z. (2019). The spatiotemporal characteristics of the coupling and coordination of green innovation efficiency and ecological welfare performance under the concept of strong sustainability. Journal of Natural Resources, 34(02), 312-324. https://doi.org/10.31497/zrzyxb.20190208

[12] Xincai, G. \& Fang, Y. (2016). Measurement of the Coordination Degree of Urbanization and Ecological Environment Coupling in Northwest China. Urban Issues,
12, 26-33. https://doi.org/10.13239/j.bjsshkxy.cswt.161204

[13] Yimeng, Z. \& Huping, S. (2018). Cooperative Evaluation of Ecological Fragility and Government Performance in Western China: An Empirical Study of 45 Cities in Western China. China Soft Science, 9, 91-103.

[14] Qiang, G. (2020). The application of deep learning method in income prediction problem. Software Guide, 19(11), 1-5. https://doi.org/10.11907/rjdk.201687

[15] Peng, S. \& Miao, Z. (2021). The VAR-LSTM framework for the prediction of national debt yield. Statistics and Decision, 5, 148-152. https://doi.org/10.13546/j.cnki.tjyjc.2021.05.032

[16] Maosen, X. \& Lingling, J. (2021). China Consumer Confidence Index Forecast Based on Deep Network CNNLSTM Model. Statistics and Decision, 7, 21-26. https://doi.org/10.13546/j.cnki.tjyjc.2021.07.004

[17] Honglin, X., He, J., Chongjun, F., \& Menda, Y. (2020). Air passenger travel index prediction based on LSTM-SVR model. Journal of System Management, 6, 1169-1176.

[18] Fanhui, K. \& Jian, L. (2020). The traffic flow prediction model of BP neural network optimized by deep belief network. Management Review, 32(3), 300-306. https://doi.org/10.14120/j.cnki.cn11-5057/f.2020.03.025

[19] Ruoyu, Q. (2019). A neural network-based stock prediction model. Operations Research and Management, 28(10), 132140. https://doi.org/10.12005/orms.2019.0233

[20] Yan, P., Yuhong, L., \& Rongfen, Z. (2019). Modeling and analysis of stock price prediction based on LSTM. Computer Engineering and Application, 55(11), 209-212. https://doi.org/10.3778/j.issn.1002-8331.1811-0239

\section{Contact information:}

\section{Chen CHEN}

School of Economics and Management,

Northeast Forestry University, Harbin, 150040, China

College of accounting and Finance,

Heilongjiang Polytechnic, Harbin, 150010, China

\section{Zhenhua QIAO}

School of Economics and Management,

Northeast Forestry University, Harbin, 150040, China

\section{Haitao SUN}

(Corresponding author)

College of Accounting and Finance,

Heilongjiang Polytechnic, Harbin, 150010, China

E-mail: huangyl2315@126.com 